\title{
Ectopia Cordis
}

\author{
Md. Hamidur Rahman ${ }^{1}$, Mahmuda Hassan², Kona Chowdhury ${ }^{3}$, Abdul Quddus ${ }^{4}$
}

${ }^{1}$ Dr. Md. Hamidur Rahman, MBBS, FCPS. Professor and Head of the department, Paediatrics, ${ }^{2} \mathrm{Dr}$. Mahmuda Hassan, MBBS, MD. Associate Professor, Department of Pediatrics, ${ }^{3}$ Dr. Kona ChowdhuryMBBS, FCPS. Assistant Professor, Department of Paediatrics, ${ }^{4}$ Dr. Abdul QuddusMBBS, FCPS. Professor and head of the department, Radiology, All from the Ad-din Women's Medical College Hospital, Dhaka.

\section{Address for correspondence:}

Dr. Mahmuda Hassan

E-mail: mahmudahasn@yahoo.com

\section{How to cite}

Md. Hamidur Rahman, Mahmuda Hassan, Kona Chowdhury, Abdul Quddus. Ectopia Cordis. J Nepal Paediatr Soc 2016;36(2):184187.

doi: http://dx.doi.org/10.3126/jnps.v36i2.14807

This work is licensed under a Creative Commons Attribution 3.0 License.

\section{(c) (7)}

\begin{abstract}
Ectopia Cordis is a rare congenital anomaly characterized by partial or complete displacement of the heart outside the thoracic cavity. Usually ectopiacordis is associated with other multiple anomalies and intra cardiac defects. The five main ectopic positions are adjacent to the thorax approximately $60 \%$, abdominal is $15-30 \%$,thoraco-abdominal is $7-18 \%$,cervical is about $3 \%$ and least is the cervicothoracic. We are reporting a case of ectopiacordis of abdominal type. This is the first reported abdominal ectopia cordis case in Bangladesh.
\end{abstract}

Key words: Ectopiacordis, cardiac defects

\section{Introduction}

Wallerfirst described the term Ectopiacordis in $1706^{1}$.The term was derived from Greek word ektopos meaning away from a place. Ectopiacordis is defined as complete or partial displacement of the heart outside the thoracic cavity. Ectopiacordis may occur as an isolated malformation or it may be associated with a large category of ventral wall defects that affect the thorax, abdomen or both. All these are due to defects in the midline due to failure of fusion in the ventral body wall in the mid line during in utero development. The incidence of Ectopiacordis is 5.5-7.9 in 1 million births, seen more in females ${ }^{2}$. In 1997 Ectopiacordis was classified into 5 types depending up on the position of the heart ${ }^{3}$.

They are:-

1. Cervical: In which the heart is located in the neck with sternum which is usually intact.

2. Thoracocervical: in which the heart is partially in the cervical region but the upper portion of the sternum is split.

3. Thoracic: in which the sternum is split or absent and heart lies partially or completely outside the thorax.

4. Thoracoabdominal: which usually accompanies Cantrell's syndrome ${ }^{4}$.

5. Abdominal: in which the heart passes through a defect in the diaphragm to enter the abdominal cavity ${ }^{3}$.

In Cantrell's pentalogythe full spectrum consists of five anomalies: A deficiency of the anterior diaphragm, a midline supraumbilical abdominal wall defect, a defect in the diaphragmatic pericardium, various congenital intracardiac abnormalities, and a defect of the lower sternum ${ }^{4}$.Ectopiacordis interna, also known as Tin

J. Nepal Paediatr. Soc. 
Man syndrome, is a rare variant of ectopiacordis in which the heart is located completely within the abdominal cavity. It is almost always an asymptomatic condition found incidentally on imaging, or less often detected by physicians when attempting to auscultate the chest or at abdominal palpation. Why is it called Tin Man Syndrome ? It is called Tin Man Syndrome because of the Tin Man in "The Wizard of Oz", who had no heart.The Wizard of Oz (1939)is an American musicalcomedy-dramafantasy film where Buddy Ebsen took the first makeup as the Tin Man.

\section{The Case}

A two months five days male child presented with cough and cold with respiratory distress for three days, also had pulsatile abdomen with pulsatile umbilical hernia since birth. Mother also complained of breathing difficulty during feeding. On general examination the baby was plethoric, cyanosed, clubbing of the nail beds of both hands and feet.

Examination of the chest exhibited fast breathing and chest in-drawing. On auscultation bilateral crepitation and rhonchi were present. No heart sound was audible in the precordium. On inspection umbilical hernia including whole abdomen was pulsatile. Heart sounds were audible on abdomen and soundscorresponds with the radial and other pulses. There was mild hepatomegaly about $3 \mathrm{~cm}$ below the right costal margin. Admission weight was $3.2 \mathrm{~kg}$,(below $3^{\text {th }}$ percentiles), OFC was 34.5 $\mathrm{cm}$ (below $3^{\text {th }}$ percentiles), length $53 \mathrm{~cm}$ ( $5^{\text {th }}$ percentiles). No abnormality was detected in any other system. On admission $\mathrm{Hb} \%$; was $11.8 \mathrm{gm} / \mathrm{dl}$, total count were $18,000 / \mathrm{cmm}$.and differential count were lymphocyte $30 \%$, polymorphs $62 \%$, eosinophil $4 \%$, monocyte $4 \%$, basophil $0 \%$, platelet count was $1,70,000 / \mathrm{cmm}$. Random blood sugar was $4.4 \mathrm{mmol} / \mathrm{L}$, serum electrolytes and serum calcium were within normal limit. Peripheral blood film showed mature white cells with above distribution. Blood culture showed no growth of bacteria. No significant antenatal history was obtained. Baby was delivered normally and perinatal and the postnatal history was uneventful. This was the $2^{\text {nd }}$ issue of a nonconsanguineous parent.

Ultrasonogram of the abdomenshowed ectopic position of the hesart seen in between liver and the spleen. Diaphragm appeared intact. Detail counselling was done with the parents regarding the nature of the disease and consequences after surgery or without surgery. Knowing all these information, party refused to do any further investigations, surgical interventions and went home with some medical advice.

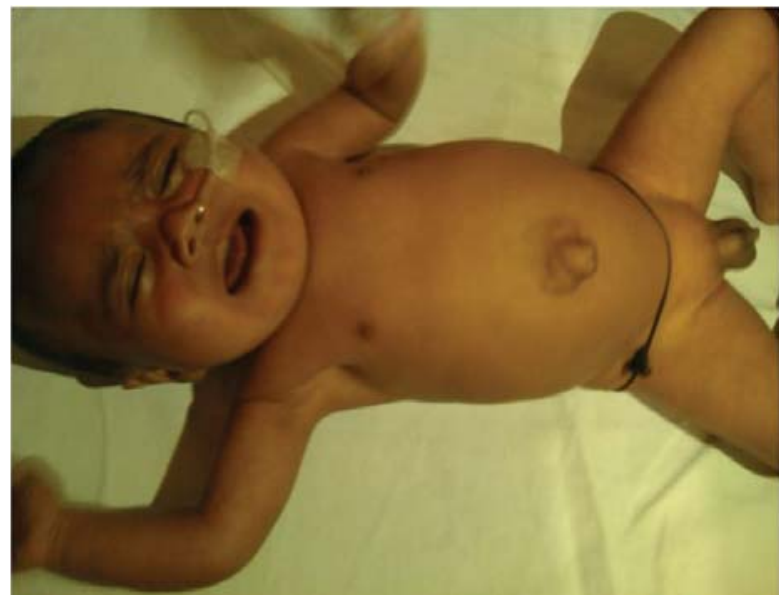

Fig 1: Baby with umbilical hernia

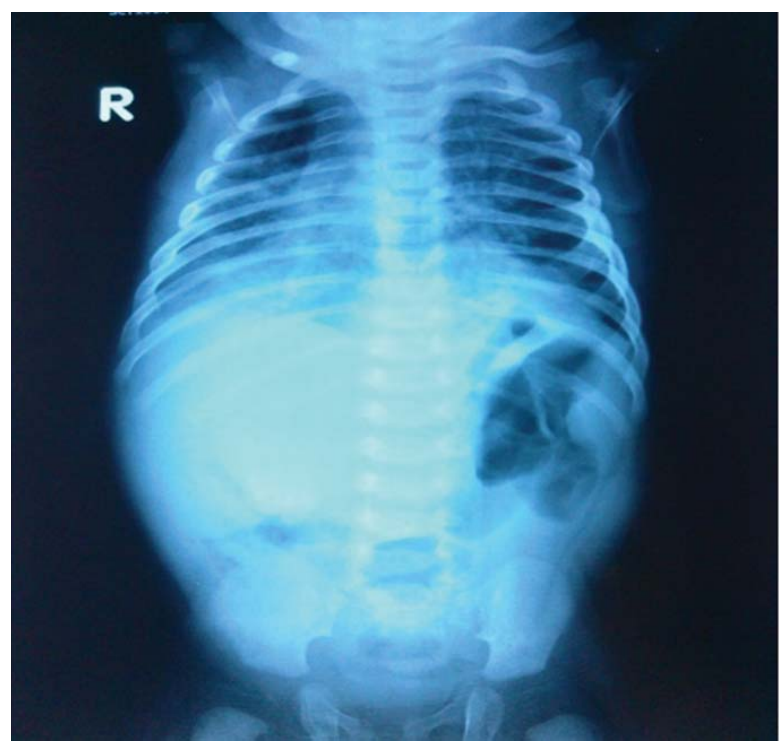

Fig 2: $X$ ray chest and abdomen, no cardiac shadow in thorax and patchy opacities in both side of the lung fields.

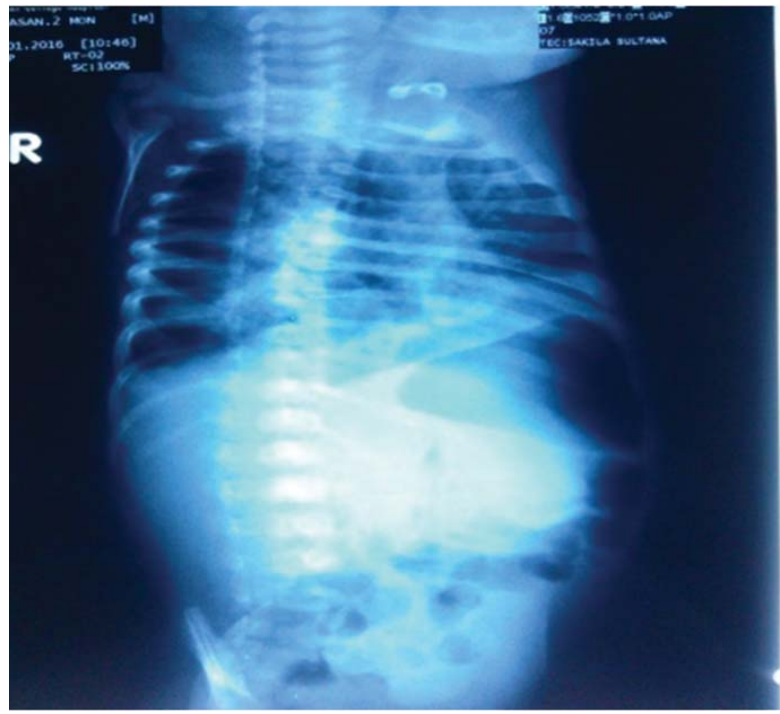

Fig 3: $X$ ray chest lateral view: confirms the absence of the cardiac shadow in thoracic cavity and extrathoracic location of the heart. 


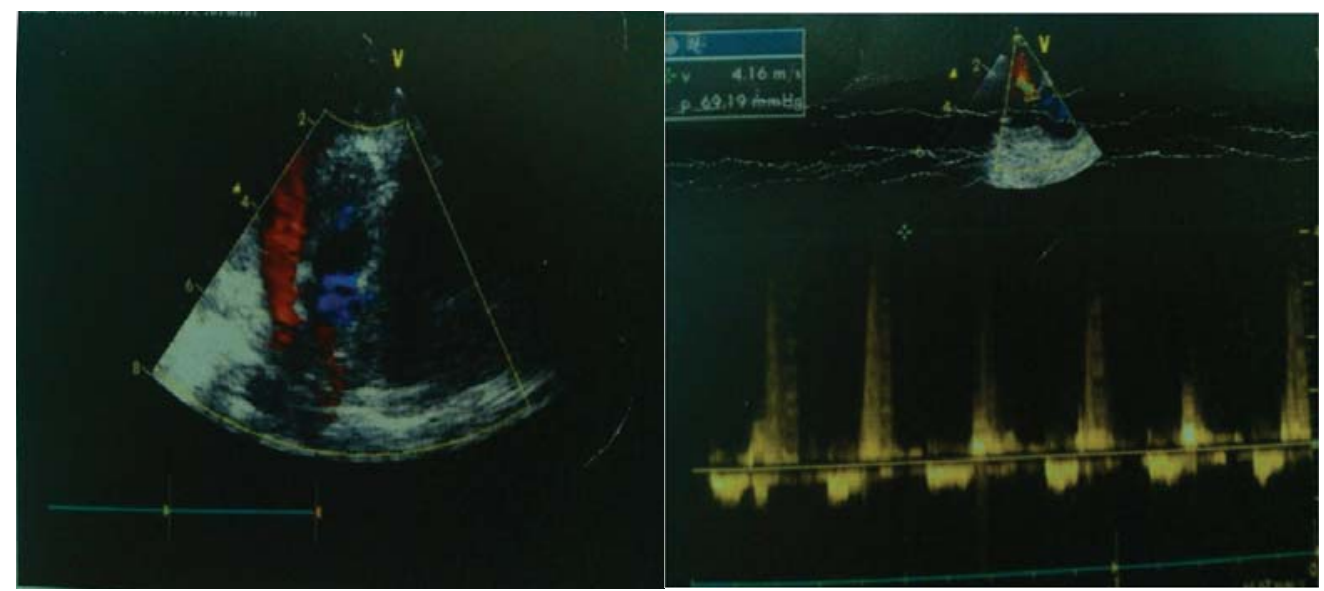

Fig 4: Echocardiographyshowed heart is in the abdominal cavity occupying the left hypochondriac region and mid umbilical region. Unbalanced complete atrioventricular septal defect (AVSD). Truncusarteriosus of type IV.

\section{Discussion}

Ectopiacordis is a rare and striking congenital heart defect, which was first observed 5000 years ago a The $^{5}$ defect was described as malposition of heart, partially or completely outside the thorax. It is a rare congenital defect in the fusion of ventral chest wall resulting in extra thoracic location of the heart. Ectopiacordis is usually associated with other congenital anomalies and intra cardiac defects ${ }^{6}$.In abdominal variety of ectopiacordis heart passes through a defect in the diaphragm to enterthe abdominal cavity ${ }^{3,7}$.Ventricular septaldefect, atrial septal defect, diverticulum of the ventricle and tetralogy of Fallot are the most common intra-cardiac defects ${ }^{8,9}$. Omphalocele is the most common abdominal wall defect. The following characteristics were observed in our patient: abdominal variety of ectopiacordis where heart was situated between liver and the spleen. Diaphragm appeared intact.Intracardiac defect was unbalanced complete AVSD and truncusarteriosus of type IV.

More severe and complex intracardiac defect associated with this malformation leads to very poor prognosis $^{8}$. This defect may also be associated with other congenital anomalies like anencephaly, hydrocephaly, cranial and facial malformations, cleft lip or palate, abdominal wall defects, neural tube defects, genitourinary or gastrointestinal malformation etc ${ }^{10,11}$. A well- known syndrome association is pentalogy of Cantrell ${ }^{12}$ which comprises of ectopicordis, omphalocele (typically supraumbilical), congenital diaphragmatic hernia, sternal cleft, congenital heart disease. Our case had no thoracic or abdominal wall defect and the heart was completely within the abdominal cavity with pulsatile abdomen and umbilical hernia. In spite of surgical treatments, few patients with these cardiac malformations survive and most of them die in the first few weeks of life. ${ }^{13}$ The prognosis of this condition is usually poor ${ }^{14}$.

\section{Conclusion}

Ectopia cordis is a rare congenital malformation. The prognosis is generally poor even after surgical correction and also depends on the severity of intracardiac malformations and the presence of associated abnormalities. Most infants are stillborn or die within the first hours or days of life.

\section{References}

1. KS Budhwani, RK Ghritlaharey, PK Jain. Haller cited in EctopiacordisThoracalis with facial cleft. Indian J Radiol Imaging2003;13(4):415-16.

2. Hornberger LK, Colan SD, Lock JE, Wessel $\mathrm{DL}$, Mayer JE. Outcome of patients with ectopia cordis and significant intracardiac defects. Circulation1996;94:32-7.

3. Kim KA, Vincent WF, Muenchow SK, Wells WJ, Downesy SE: Successful repair of ectopiacordis using alloplastic materials. Ann Plastic Surg1997;38:51822.

4. Cantrell JR, Haller JA, Ravitch MM. A syndrome of congenital defects involving the abdominal wall, sternum, diaphragm, pericardium, and heart. SurgGynecol Obstet1958;107(5):602-14. 
5. Taussing HB: World survey of the common cardiac malformation: developmental error of genetic of genetic variant. Am J Cardio/1982;50:544-59.

6. Jahanara Arzu, Abu Siddique, S K Banerjee et al. Case Report : ectopiacordis. University Heart Journal, Bangabandhu Sheikh Mujib Medical University.2013;9(2):119-120.

7. Dobell AR, William HBU, Long RW: Stage repair of ectopiacordis. J Pediatr Surg1982;17:353-58.

8. Amato JJ, Zelen J, Talwakar NG. Single stage repair of thoracic ectopi cordis. Ann ThoracSurg 1995;59:518-20.

9. Leca F, Thibert N, Khoury W,Fermont L, Laborde F, Dumez Y. Extrathoracic heart (ectopia cordis): report of two cases and review of literature. Int $J$ Cardiol 1989;22:221-28.
10. Hochberg J, Ardenghy MF, Gustafson RA, Murray GF. Repair of thoracoabdominal ectopia cordis with muco-cutanuous flaps and intra operative tissue expansion. Plast Reconstr Surg 1995;95:148-51.

11. Diaz JH. Perioperative management of neonatal ectopia cordis: report of three cases. Anest Analg 1992;75:833-7.

12. Kumar B, Sharma C, Sinha DD et-al. Ectopiacordis associated with Cantrell's pentalogy. Ann Thorac Med 2008;3(4):152-53.

13. Cabrera A, Rodrigo D, Luis T, Pastor E, Galdeano JM, Estaban S. Ectopia cordis and cardiac anomalies. Rev EspCardiol 2002; 55:1209-12.

14. Mohamed S. Kabbani, Khalid Rasheed, Mohammed S. Mallick Hannan Abu-Hassan, Saad Al-Yousef. Thoraco-abdominal ectopia cordis: case report. Ann Saudi Med 2002;22(5-6):366-368. 